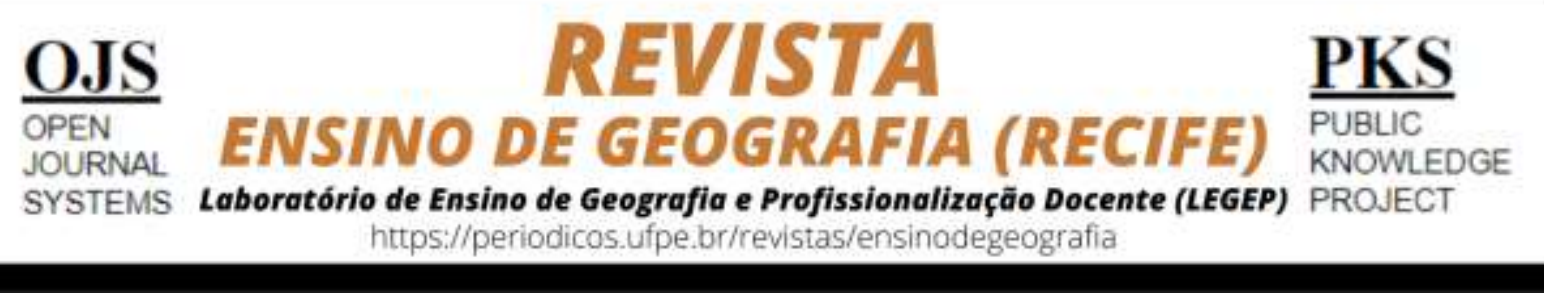

\title{
CONTRIBUIÇÕES DO PIBID-GEOGRAFIA PARA A FORMAÇÃO INICIAL DE PROFESSORES E OS DESAFIOS NO ENSINO DE CARTOGRAFIA
}

\author{
Louislane Araujo Pinto ${ }^{1}$, Roberto Antero da Silva ${ }^{2}$, Mauricio Ferreira Mendes ${ }^{3}$
}

\begin{abstract}
${ }^{1}$ Graduanda em Geografia na Universidade Federal de Tocantins. E-mail: louislane.araujo@uft.edu.br - ORCID iD: http://orcid.org/0000-0002-7616-1025

${ }^{2}$ Professor do curso de Geografia da Universidade Federal do Tocantins. E-mail: robertoantero@uft.edu ORCID iD: http://orcid.org/0000-0003-0832-4539

3Professor do curso de Geografia da Universidade Federal do Tocantins.E-mail: mauricio.mendes@uft.edu.br ORCID iD: http://orcid.org/0000-0003-4801-0227
\end{abstract}

Artigo recebido em 27/03/2020 e aceito em 06/04/2020

\begin{abstract}
RESUMO
Experiências vivenciadas na prática de sala de aula são essenciais para a formação inicial de professores. Nesse contexto, o presente artigo teve como objetivo apresentar contribuições para a formação inicial de professores em Geografia por meio de experiências vivenciadas no âmbito do Programa Institucional de Bolsa de Iniciação à Docência (PIBID) da Universidade Federal do Tocantins (UFT), campus de Araguaína, referente ao período de 2018 a 2019, pautando a educação cartográfica. Para tanto, utilizou-se técnicas de estudo de caso aplicadas no Colégio Estadual Adolfo Bezerra de Menezes, localizado em Araguaína/TO como laboratório de aprendizagens e também espaço de formação docente, associada a pesquisa qualitativa, onde o pesquisador trabalha com o universo de fenômenos. Conclui-se que o PIBID é extremante importante, visto que o programa fornece elementos chaves na articulação de diversas instruções no processo de ensino/aprendizagem, na aplicação de novas metodologias, proporcionado uma troca de saberes, pautando a teoria/prática, obtendo resultados positivos na formação de professores para atuação na Educação Básica.

Palavras-chave: Cartografia; ensino/aprendizagem; formação de professores; PIBID; Tocantins.
\end{abstract}

\section{PIBID/GEOGRAPHY CONTRIBUTIONS TO INITIAL TEACHER TRAINING AND CHALLENGING TEACHING CHALLENGES}

\begin{abstract}
Experiences in classroom practice are essential for initial teacher education. This article aims to present contributions to the initial formation of teachers in Geography through experiences lived within the Institutional Program of Teaching Initiation Scholarship (PIBID) of the Federal University of Tocantins (UFT), Araguaína campus, referring to the period 2018 to 2019, guiding the cartographic education. . For this, we used case study techniques applied at Adolfo Bezerra de Menezes State College, located in Araguaína/TO as a learning laboratory and also a space for teacher training, associated with qualitative research, where the researcher works with the universe of phenomena. It is concluded that the PIBID is extremely important, since the program provides key elements in the articulation of several instructions in the teaching/learning process, in the application of new methodologies, providing an exchange of knowledge, guiding the theory/practice, obtaining positive results in the formation of teachers to act in Basic Education.
\end{abstract}

Keywords: Cartography; teaching/learning; teacher training; PIBID; Tocantins. 


\section{INTRODUÇÃO}

Este artigo objetiva apresentar contribuições para a formação inicial de professores em Geografia, bem como os desafios à prática docente, por meio de experiências vivenciadas no âmbito do Programa Institucional de Bolsa de Iniciação à Docência (PIBID) da Universidade Federal do Tocantins (UFT), campus de Araguaína, referente ao período de 2018 a 2019, pautando a educação cartográfica e estabelecendo novas estratégias de ensino.

O PIBID permite a inserção do acadêmico no ambiente escolar e amplia possibilidades de reflexões de debates juntamente com professores e alunos da escola, contribuindo para geração de conhecimentos e aprendizagens, evidenciando assim os desafios à prática docente. [...] "Ao conceber a escola como ambiente de formação durante o cursar da Licenciatura, fomentasse a profissão docente articulada ao efetivo contexto das escolas de Educação Básica" (WOITOWICZ e SCHLOSSER, 2018, p. 30).

Sendo assim, ao tomar conhecimento do espaço escolar, o aluno tem um ambiente propício ao desenvolvimento de diversas práticas de investigação, tornando a escola um laboratório vivo para a prática docente e o crescimento profissional, além de despertar o interesse do aluno pela profissão professor.

Para tanto, utilizou-se técnicas de estudo de caso no Colégio Estadual Adolfo Bezerra de Menezes, localizado no município de Araguaína/TO (Figura 1) como laboratório de aprendizagens e espaço de formação docente, por meio da participação de 5 (cinco) bolsistas de iniciação à docência, que integraram o projeto. Utilizou-se a pesquisa qualitativa, onde o pesquisador "trabalha com o universo de significados, motivos, aspirações, valores e atitudes, o que corresponde a um espaço mais profundo das relações, dos processos e dos fenômenos" (GERHARDT e SILVEIRA, 2009, p. 32).

No âmbito educacional existem vários obstáculos a serem superados, visando sempre uma educação melhor e de qualidade a todos os cidadãos. O Colégio Adolfo Bezerra de Menezes é uma escola de grande porte, oferece Educação Básica a 1780 (Mil setecentos e oitenta alunos) alunos, o colégio passa por dificuldades no sistema de ensino-aprendizagem, tendo alunos indisciplinados e com falta de atenção e concentração nas aulas, e também dificuldades financeiras, não tendo recursos para compra de materiais didáticos e/ou realização de aula-campo, somente para exemplificar. 
Figura 1. Localização do Colégio Estadual Adolfo Bezerra de Menezes na mancha urbana de Araguaína (TO).

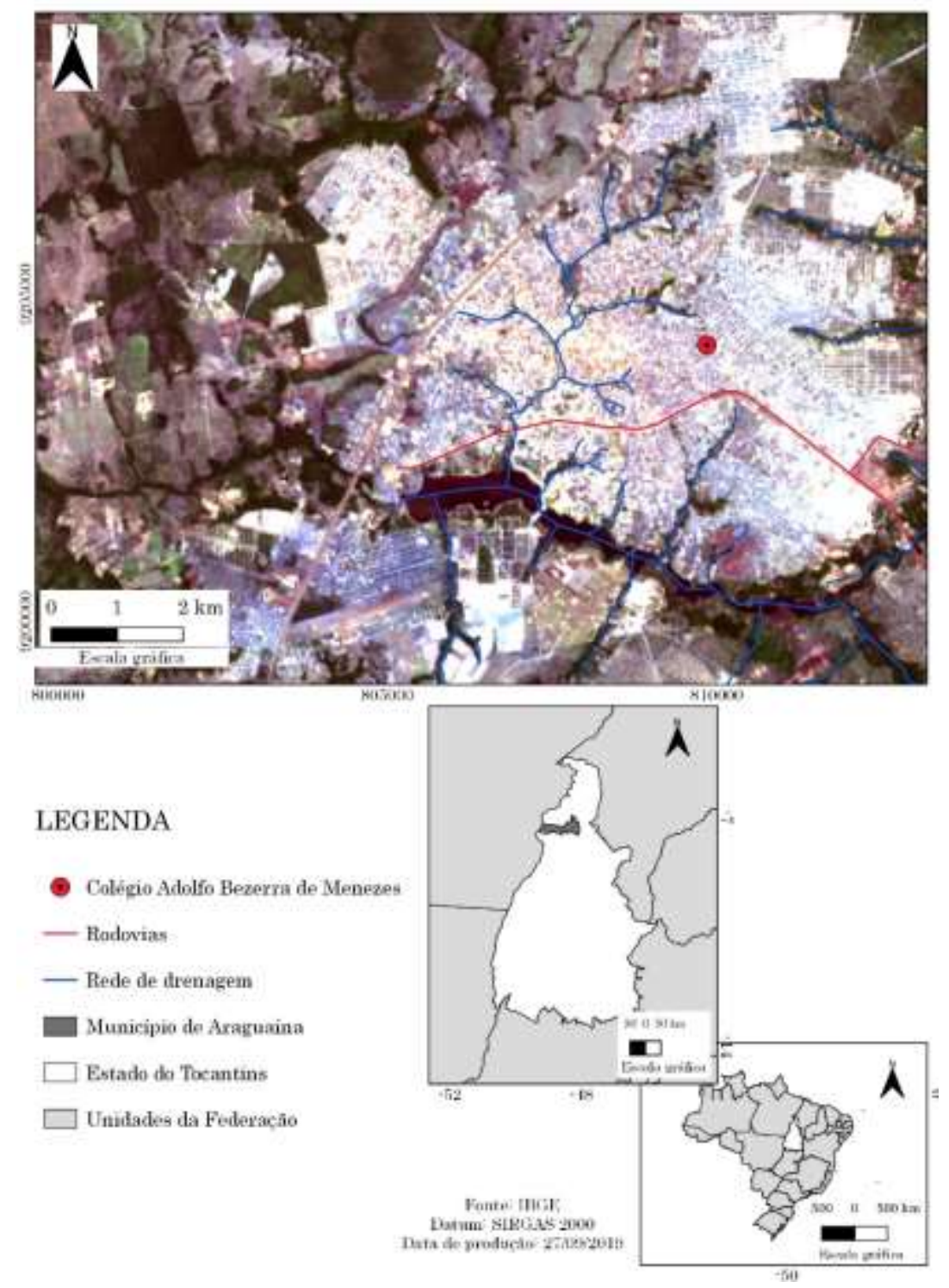

Fonte: os autores (2019).

Soma-se a isso, o ataque do atual governo a educação brasileira, principalmente com corte de recursos financeiros para fins de sucateamento e posteriormente privatização da Instituições de Ensino Superior (IES). Esses cortes orçamentários de maneira geral, não são percebidos pela população, mas sim pelos gestores, professores e principalmente pelos alunos que não tem mais certeza se conseguirão terminar o curso em uma universidade pública e de qualidade.

Foi observado na escola a falta de interesse pelos conteúdos de Geografia e em especial dificuldade dos alunos com a cartografia, tendo assim a oportunidade dos pibidianos da UFT atuarem com a realização de atividades práticas para o entendimento do conteúdo, além de 
outras atividades que contribuíram para o processo ensino-aprendizagem dos alunos, tendo o projeto PIBID de Geografia como um espaço de construção de conhecimentos no dia-a-dia e coletivamente.

A partir dessa constatação, foi realizada oficinas de cartografia e jogos didáticos no Colégio Adolfo Bezerra de Menezes, com o intuito de ampliar a educação cartográfica, evidenciando noções, conceitos e a utilização de práticas dos mapas, tanto dentro como fora da escola. Também os alunos da escola foram até a UFT, para conhecer o Laboratório de Cartografia e Estudos do Território (LCET).

O texto apresenta, além dessa introdução, das considerações finais e das referências bibliográficas, uma discussão sobre a importância da cartografia para o ensino de Geografia, destacando as contribuições do PIBID de Geografia neste processo e por fim enfoca a relação da teoria e prática na formação docente por meio das oficinas de cartografia e jogos didáticos realizado pelos alunos pibidianos, professores da escola e da UFT.

\section{A IMPORTÂNCIA DA CARTOGRAFIA PARA O ENSINO DE GEOGRAFIA}

A cartografia é a ciência responsável pela representação gráfica da superfície física, desde a sua concepção, conceitos, produção e disponibilização de mapas. A cartografia faz parte do ensino das Escolas de Educação Básica de todo o país, e é fundamental para entendimento e compreensão do espaço geográfico brasileiro e mundial (BAGGIO e CAMPOS, 2017).

\footnotetext{
Ela [a cartografia] possibilita a compreensão de diversos conteúdos chaves relacionados à Geografia (espaço, região, lugar, território, paisagem, sociedade); propicia reflexões ambientais e multiculturais; possibilita que o aluno visualize e reconheça o mundo ao qual pertence, de modo que possa locomover-se nele e como representá-lo. Paira socialmente a ideia de que cabe à escola ensinar a ler, escrever e fazer contas, dando a entender que apenas isso é importante para o aprendizado do aluno. Porém, é preciso que ele seja preparado pela escola para o domínio espacial, com materiais didáticos adequados, que proporcionem aulas de qualidade (BAGGIO e CAMPOS, 2017, p. 2).
}

É importante destacar que a cartografia é representada desde a pré-história, no qual os seus conhecimentos sobre o uso da caça e pesca eram representados, e, para isso, fizeram uso dos recursos de que dispunham, como a argila, o papiro, as peles de animais ou as inscrições rupestres. "Estes são exemplos da importância da representação dos espaços de vivência para a própria sobrevivência dos grupos humanos [...], para as quais o desenho dos itinerários e dos pontos de interesse a eles associados eram vital" (CARVALHO e ARAÚJO, 2008, p. 3-4)). 
Os Parâmetros Curriculares Nacionais (PCN's) também dão ênfase ao ensino de cartografia, destacando o papel do professor para que desperte a imaginação dos alunos, passando a utilizar recursos didáticos. "A cartografia torna-se recurso fundamental para o ensino e a pesquisa. Ela possibilita ter em mãos representações dos diferentes recortes desse espaço e na escala que interessa para o ensino e pesquisa" (BRASIL, 1997, p.76).

A Base Nacional Comum Curricular (BNCC, 2017, p. 362) tem como uma das unidades temáticas do componente curricular geografia as "formas de representação e pensamento espacial". O documento curricular também destaca a necessidade de "alfabetização cartográfica" nos cinco primeiros anos do ensino fundamental.

Porém, Castellar (2014) destaca que a BNCC é meramente conteudista e que não permite o aprofundamento de temas importantes da educação básica. A autora acredita que é necessário buscar "formas de ampliação do espaço educativo que rompam os limites físicos dos muros escolares, incorporando às práticas docentes metodologias que mudem a cultura escolar em relação ao processo de ensino e de aprendizagem" (FERRACINI, 2014, p.30).

Portanto, a cartografia e a Geografia devem caminhar juntas, na busca pelo saber. É muito importante que a cartografia esteja sempre presente no ensino de Geografia, nas aulas e na prática da disciplina, apesar de não ser algo simples para os alunos compreenderem, pois muitos já veem que a cartografia é apenas a interpretação de mapas, não dando assim um olhar de problematização a mesma, e por parte dos professores, não abordando de maneira dinâmica e contextualizando com o conhecimento dos alunos (SANTOS, et al., 2011).

Podemos perceber que o ensino da cartografia atualmente vem sendo modificada, ou seja, foram inseridas novos métodos de aprendizagem, sobre tudo com os avanços da internet, como inserção das geotecnologias, esses recursos fizeram grandes mudanças no ensino da cartografia na escola e principalmente nas universidades, visto que permite ao aluno conhecer o mundo sem sair do lugar (ALMEIDA e ALMEIDA, 2014).

Portanto, para que o aluno tenho um melhor entendimento do espaço geográfico, cabe a escola oferecer oportunidades de conhecimentos e aprendizagens, fazendo uso de matérias didáticos, mapas, jogos didáticos para que o aluno possa pensar e refletir sobre a organização espacial, como vem acontecendo no Colégio Estadual Adolfo Bezerra de Menezes. Segundo Francischett (2001, p. 38) “[...] linguagem cartográfica é um aspecto de relevante importância, principalmente quando se trata de pensar na educação do indivíduo habilitado [...]”. É preciso que seja apresentado a cartografia aos alunos, contextualizando as explicações dos símbolos, 
da linguagem cartográfica, apresentando-lhes a importância da leitura dos mapas para o exercício do pensamento crítico e exercício da cidadania. Nesse contexto, Souza e Katuta (2001) afirma:

Os conhecimentos cartográficos têm uma estreita relação com a crítica do pensamento geográfico. É preciso, portanto, encarar a cartografia além de seus aspectos visuais e artísticos, propondo alternativas para sua utilização e objetivando a compreensão da realidade que o indivíduo vive e que pode ser transformada (SOUSA e KATUNA, 2001, p. 12).

Nas oficinas de cartografia e jogos didáticos realizado no Colégio Adolfo Bezerra de Menezes é exatamente isso que ocorre, os professores da escola juntamente com os alunos do PIBID trabalham com a interpretação de mapas, localização no espaço com o intuito do desenvolver o pensamento crítico e reflexivo, abrindo caminho para o aluno se aproprie do conhecimento, tenha autonomia e se interesse pela cartografia e Geografia.

Porém, sabemos que existem muitos problemas nas escolas como falta de materiais didáticos, mapas, globos terrestres, computadores, não tendo recursos financeiros para adquirilos. Outro fator limitante, é que ainda algumas escolas não possuem laboratório de informática, que é uma ferramenta importante e atual para o ensino da cartografia.

Além disso, não basta as escolas adotarem novas tecnologias, comprar equipamentos sofisticados e melhorar a estrutura física, se não forem realizadas capacitações e formação de professores para atuarem com esses novos instrumentos (MARCEDO, 1999).

Segundo Freire (2011), apesar de muitos obstáculos vivenciados na educação brasileira, como desvalorização do professor, falta de recursos financeiros, inexistência de políticas de formação continuada, devemos resistir, lutar e a educação e a formação de pensamentos críticos podem contribuir para uma sociedade melhor.

Por isso, a importância e a manutenção do PIBID/Geografia nas escolas de Araguaína, uma vez que a parceria universidade $\mathrm{x}$ escola podem trazer resultados positivos, propiciando a utilização de recursos metodológicos que estabeleçam as relações entre os fenômenos, demonstrando na prática suas espacialidades, tornando assim as aulas mais atraente para os alunos. Portanto, o PIBID permite experimentar todas essas especificidades da educação na formação inicial, como veremos próximos tópicos. 


\section{O PIBID/GEOGRAFIA DA UFT E AS CONTRIBUIÇÕES PARA A FORMAÇÃo INICIAL DE PROFESSORES E A CARTOGRAFIA}

O PIBID é uma ação da Política Nacional de Formação de Professores do Ministério da Educação (MEC), dando a oportunidade aos estudantes de licenciaturas a terem uma vivência cotidiana nas escolas públicas de Educação Básica. "O programa concede bolsas a alunos de licenciatura participantes de projetos de iniciação à docência desenvolvidos por Instituições de Educação Superior (IES) em parceria com as redes de ensino" (CAPES, 2019, p.1).

Assim, como para a Coordenação de Aperfeiçoamento de Pessoal de Nível Superior (Capes), no âmbito da UFT, o PIBID tem por finalidade fomentar a iniciação à docência, contribuindo para o aperfeiçoamento da formação de docentes em nível superior e para a melhoria da qualidade da Educação Básica pública brasileira.

A UFT, por meio da Pró-Reitoria de Graduação (Prograd) vem atuando junto ao PIBID desde o edital da Capes de 2007. A proposta do PIDID/UFT para execução de 2014 a 2018 foi composto por 22 (vinte e dois) subprojetos, incluindo os cursos de Geografia, Física, Química, Biologia, História, Pedagogia, Filosofia, Letras e Matemática, sendo executado em parcerias com escolas públicas de Educação Básica, por meio de parceria com as Diretorias Regionais de Ensino (DREA's) do estado do Tocantins.

A execução do PIBID na UFT, tem se fundado nos seguintes objetivos, o incentivo a formação de professores em nível superior para a Educação Básica; a contribuição da formação inicial de professores, por meio da integração entre Educação Básica e Superior; e a inserção de alunos no cotidiano de escolas da rede pública, dando oportunidades para aprendizados, vivencias e trocas de saberes juntamente com os professores das escolas, contribuindo diretamente para articulação teoria e prática.

No caso específico da Geografia da UFT/Araguaína, o subprojeto do curso compreende um total de 5 (cinco) bolsas, com atuação no Colégio Adolfo Bezerra de Menezes, nível ensino fundamental, séries finais, na modalidade de ensino regular. Os alunos atuam na prática em seu futuro ambiente de trabalho, desenvolvendo metodologias ativas, principalmente na área de cartografia, para contribuir no processo ensino/aprendizagem.

No planejamento das atividades das atividades do alunos de Geografia da UFT para os anos de 2018 e 2019 foram elencadas 5 (cinco) resultados (impactos): 1) reconhecimento do espaço escolar; 2) Desenvolvimento de atividades formativas e didático-Pedagógicas; 3 ) 
implementação de novas estratégias de ensino; 4) sistematização de erros e acertos e; 5) socialização dos resultados. Para cada impacto foi determinado os indicadores de impacto, bem como as atividades para atingir esses resultados, e elencado os alunos e professores responsáveis por cada atividade, além de prazos estabelecidos.

Os alunos do programa são sempre acompanhados por professores supervisores do colégio e da UFT, que são responsáveis pelo planejamento e andamento das atividades desenvolvidas de ensino. Neste contexto, Freitas (2016, p. 27) aponta:

Os bolsistas, ao levarem para a escola o conhecimento adquirido durante a graduação, muitas vezes percebem que a teoria aprendida é insuficiente diante das demandas da prática escolar. Durante o processo de construção do projeto de pesquisa, retornam ao grupo imersos em inquietações e perplexos com o cotidiano escolar. Ao confrontarem o senso comum, o conhecimento geográfico e o conhecimento pedagógico, sentem a necessidade de expor as suas dúvidas e angústias (FREITAS, 2016, p. 27).

É fundamental destacar que o PIBID/UFT possibilita ao estudante de licenciatura em Geografia a oportunidade ter um convívio próximo com o professor da escola e consequentemente ocorrer a geração de troca de conhecimentos e oportunidades de novos aprendizados, além do que permite que o aluno analise o funcionamento da escola como um todo, observando o andamento das aulas e a aplicação de metodologias em seu futuro local de trabalho.

Também participa no planejamento de aulas, contribuindo no desenvolvimento de formas mais interativas e inovadoras de trabalhar os conteúdos em sala de aula, para melhor resultados no processo ensino/aprendizagem. Como também, tendo suas primeiras frustrações, pois o trabalho profissional dos professores na grande maioria das vezes, não são reconhecidos pelos governos, pelos pais e pela sociedade de maneira geral.

Os alunos do PIBID/UFT analisam o Projeto Político Pedagógico (PPP) da escola, com intuito de conhecer como funciona o planejamento e a proposta educacional da escola. É através do PPP que são apresentados as metas e objetivos e quais são as estratégias para alcançá-las. Assim, foi importante também conhecer o espaço escolar, o funcionamento dos laboratórios de informática e ciências, sala de professores, sala de planejamento, quadra de esporte e outras dependências, além de outros espaços de convivência

Destarte, Nunes (2000) chama a atenção para formação contínua do professor que se estabelecem entre as várias dimensões, seja ela formação acadêmica com participação em 
projetos como o PIBID, prática pedagógica cotidiana, pesquisa em educação, articulando teoria e prática, no intuito de compreendê-las como elementos centrais na formação de professores.

A formação do professor, como visto, é bastante complexa, existem vários obstáculos a serem enfrentados. O PIBID/UFT do curso de Geografia é uma oportunidade para muitos alunos conhecerem os obstáculos a serem enfrentados, também como é significante contribuir para o ensino/aprendizagem, seja por um auxílio na resolução de um simples exercício, seja pela construção coletiva de conhecimentos, possibilitando uma rica experiência na formação inicial.

Os alunos pibidianos da UFT aprendem desde o início que os conhecimentos devem ser compartilhados, bem como o incentivo a continuidade dos estudos para que possam no futuro influenciar em uma sociedade mais justa e humana para todos.

\section{OFICINAS DE CARTOGRAFIA E JOGOS DIDÁTICOS REALIZADOS PELOS ALUNOS DO PIBID/UFT}

Muitas vezes o ensino e a aprendizagem de cartografia não é tarefa fácil, visto que temos enormes desafios na educação, como inexistência de laboratórios e falta de professores com formação específica. No estado de Tocantins, muitas vezes, professores de outras áreas, ministram a disciplina de Geografia, principalmente em municípios mais afastados, contribuído diretamente para a falta de interesse dos alunos pela cartografia e pela própria Ciência Geográfica.

No colégio Adolfo Bezerra de Menezes, todos os professores são formados em Geografia, porém os próprios professores da escola observam dificuldades no ensino de cartografia, seja pela indisciplina do aluno, seja por acreditar que se trata de conteúdo difícil e que não traz interesse pelo aluno, tornando grandes obstáculos para o professor em sala de aula.

Segundo Pimenta e Carvalho (2008, p. 24) no ensino e aprendizagem, além do domínio específico dos conteúdos é necessário “também o domínio dos elementos que caracterizam uma prática educativa consistente e crítica". Para isso, é fundamental refletir sobre o ensino de Geografia e propor avanços, como a implementação de metodologias ativas, uma vez que essas estratégias podem gerar resultados positivos e mudar a realidade da escola.

Refletir dobre o ensino da Geografia escolar e a formação de seus profissionais requer considerar a importância do conhecimento geográfico e o papel da disciplina frente à complexidade do mundo atual. Para esse entendimento, são destacadas questões 
fundamentais como: por que ensinar Geografia? Qual a contribuição da disciplina na formação básica? (OLIVEIRA, 2012, p. 2).

Sendo assim, a ciência Geográfica é imprescindível para o exercício da cidadania e para compreensão do mundo. "É preciso que haja concepções teórico metodológicas capazes de permitir o reconhecimento do saber do outro, a capacidade de ler o mundo da vida e reconhecer a sua dinamicidade [...]" (CALLAI, 2005, p. 231).

Pimenta e Carvalho (2008, p. 3) afirmam que o ser humano é um projeto inacabado, visto que estamos em constante mudança. "Estamos em constante mudança em função das necessidades que historicamente nos tem sido postas, como ex.: afetivas, lúdicas, cognitivas, estéticas, éticas, espirituais, culturais, econômicas, sociais e políticas"

Portanto, o professor precisa perceber essas mudanças e estabelecer diferentes métodos de aprendizagens, visto que os alunos são diferentes e um único método não consegue abarcar toda a coletividade. Sendo assim, a oficina de cartografia e jogos didáticos contribuiu diretamente para inserção de um método inovador de aprendizagem na escola, tornando a atividade atraente para os alunos.

Para que atividade traga resultados, é fundamental que o professor selecione os conteúdos, objetivos, metodologias, relacionando com os conhecimentos e as práticas dos alunos. A partir desses passos iniciais, os pibidianos em conjunto com os professores da escola e da UFT, elaboraram uma oficina de cartografia, tendo o jogo didático como o principal recurso.

A oficina de cartografia fez com que os alunos tivessem outra visão da compreensão do espaço e da realidade local, além de ser um jogo cartográfico, é também uma atividade que permite compreender os conceitos de espaço, território, paisagem, política, ensinado o estudante a tomar decisão.

A Geografia é a ciência que proporciona ao aluno entender os conceitos de território, paisagem, espaço e política, além disso permite ao aluno perceber o espaço geográfico como resultado da interligação entre sociedade e natureza, destacando as contradições e marginalização de vários grupos sociais existentes no mundo. "A abordagem direta dos conceitos, associados aos conteúdos estudados na Geografia, torna-os instrumentos para a efetiva aprendizagem e permite compreender mais efetivamente a sociedade" (LISBOA, 2007, p. 23). 
Lisboa (2007) afirma que os conceitos geográficos têm a finalidade de servir como uma "ferramenta" nas análises que devem ser compreendidas e processadas pelos alunos, não podendo pensar nos conceitos como algo pronto e inacabado e sim construído coletivamente, uma vez que eles estão em constante transformação.

Brenda (2013) destaca a contribuição do jogo didático no ensino/aprendizagem da Educação Básica:

O jogo didático por ser um facilitador do conhecimento, pode ser aplicado na educação não como único meio de aprendizagem, mas como um suporte, que pode desenvolver na criança a vontade de aprender. Pode levar, inclusive, a questionamentos que desenvolvam seu raciocínio crítico, contribuindo para agregar conhecimento. A aquisição de conhecimento, feita de forma natural, sem que a criança perceba essa assimilação, é que torna o aprendizado prazeroso (BRENDA, 2013, p. 7).

A oficina de cartografia implementada no Colégio Estadual Adolfo Bezerra de Menezes foi uma grande oportunidade a todos os pibidianos vivenciarem, visto a oportunidade de elaboração, apresentação, ensinamento, aprendizagem e avaliação com os alunos, evidenciando que diferentes linguagens e/ou metodologias podem trazer resultados positivos.

O educador, comprometido com a transformação social, precisa buscar, nas dificuldades dos seus educandos, uma didática que surja dessa ação, e que, na prática educativa, o diálogo gerado entre educando e educador possa mostrar caminhos para a construção de uma pedagogia crítica comprometida com a parcela da população marginalizada pelo sistema capitalista de produção (MOURA E ALVES, 2002, p. 317).

A oficina de cartografia e jogo didático foi elaborado em conjunto com professores da escola e da UFT, tendo como público alvo os alunos do $7^{\circ}$ ao $9^{\circ}$ ano do Ensino Fundamental. Para tanto utilizou-se mapas, botões coloridos representando os exércitos, cartas geográficas, fotografias, além de computadores.

Um dos primeiros passos foi uma reunião de planejamento no Colégio Estadual Adolfo Bezerra de Menezes para definir conteúdos, metas e objetivos (Figura 2) e o segundo passo foi trabalhar na orientação dos alunos em sala de aula (Figura 3) para o entendimento de conceitos geográficos. 
Figura 2. Reunião de planejamento no Colégio Estadual Adolfo Menezes.

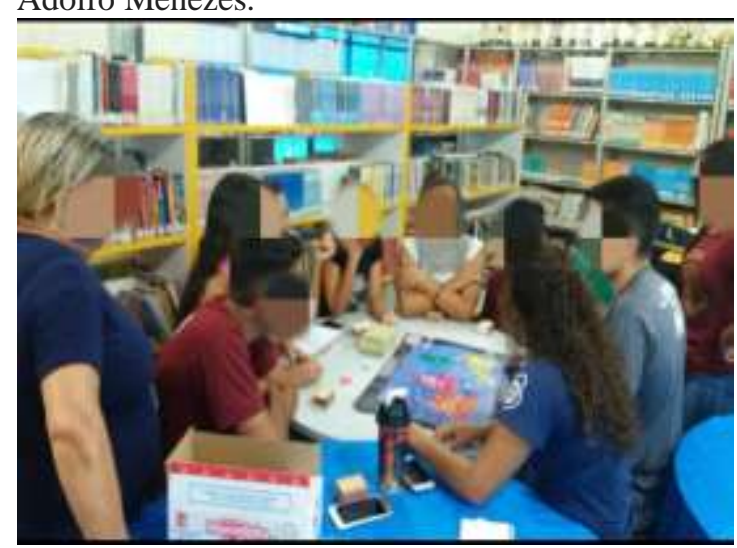

Figura 3. Orientação dos alunos em sala de aula.

Fonte: A autora (2018).

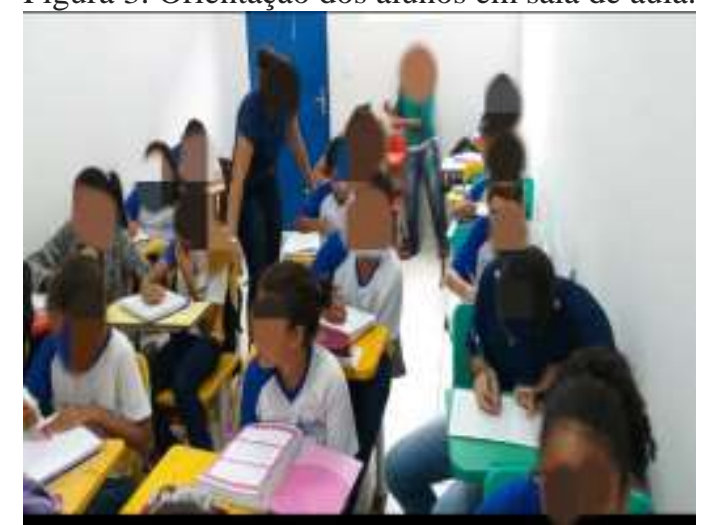

Fonte: A autora (2018).

O terceiro passo foi explicar o jogo para os alunos em sala de aula, tendo como base a oficina de cartografia (Figuras 4ab). No início foram desenvolvidas atividades referentes ao espaço geográfico mundial (América do Sul, América Central, América do Norte, África, Europa Ocidental, Europa Oriental, Ásia e Oceania) sendo essas regiões divididas em diversas cores.

Cada aluno recebia uma carta com uma missão (objetivo) em relação a um continente, que deveria ser cumprido. Mas o aluno só podia partir para sua tarefa assim que defendesse seu território (continente) com dados históricos, sobre o relevo, clima, hidrografia, vegetação, entre outros que os alunos quisessem pontuar.

Figura 4. Oficina de cartografia e jogos didáticos no Colégio Estadual Adolfo Menezes.

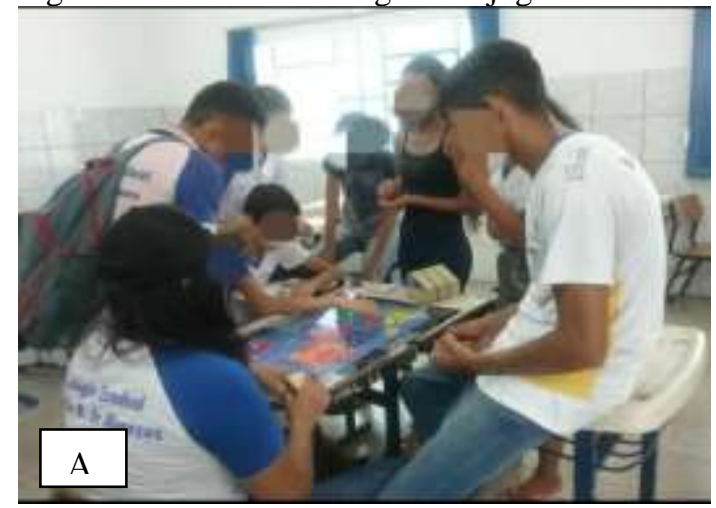

Fonte: A autora (2018).

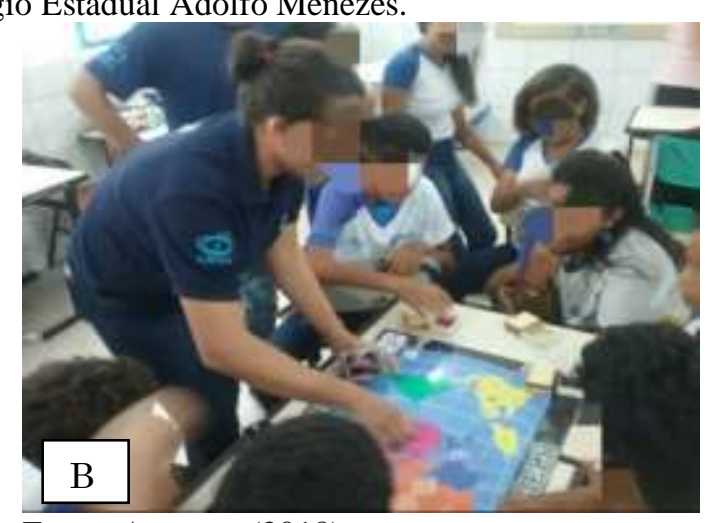

Fonte: A autora (2018).

Os alunos poderiam iniciar a oficina de cartografia e jogo didático optando em cumprir a missão ou defendendo seu território, sendo que este dependia do dado sorteado, sendo o branco para defender o território e o vermelho para avançar (atacar). 
O jogo só termina quando um dos competidores concluía sua missão, atingindo seu objetivo. O jogador que tivesse um raciocínio rápido teria uma melhor análise do jogo, podendo assim, sair na frente, além de ter sorte no sorteio dos dados. Os pibidianos sempre estiveram presentes em cada etapa da oficina, acompanhando e orientando os alunos, tirando dúvidas, pois o jogo estimula os alunos a adotarem as estratégias certas, sempre alinhando os conhecimentos geográficos, caracterização socioeconômica dos continentes e como eles estão representados nos mapas.

Nas etapas finais da oficina de cartografia, percebiam-se como o ânimo de cada aluno que participava do jogo se transformava, seja porque respondeu corretamente as perguntas, seja porque foram ajudados pelos colegas. Portanto, o jogo foi primordial para motivá-los, destacando a importância de adoção de novas metodologias para o ensino de cartografia nas escolas.

A quarta e última etapa da oficina foi a elaboração de mapas pelos alunos da escola, relacionando teria e prática. Os mapas foram feitos em papel pardo orientado pelos professores e pibidianos e posteriormente apresentados para toda a turma, cada grupo apresentou dados físicos e socioeconômicos de uma região brasileira (Norte, Nordeste, Centro-Oeste, Sudeste e Sul).

Em toda as etapas da oficina foram observadas que os alunos interagiram com os conteúdos sobre o espago geográfico brasileiro e mundial, possibilitando o alcance dos objetivos, podendo esta ser replicada em outras escolas de Araguaína.

Destarte, foi muito bem aceito o jogo pelos alunos, pois com as atividades, eles puderam compreender sobre o conceito de território, paisagem, espaço e política, temas que são abordados na Geografia, sendo a cartografia não só importante para estudos geográficos, mas também para outras áreas, como história, biologia, sociologia, entre outras. Para Brenda (2013), os jogos estão presentes na natureza dos seres humanos, desde a sua infância perpassando a sua fase adulta, visto que, abrange diversos significados, temas e imaginário das pessoas.

Infelizmente atividades dessa natureza e programas como o PIBID estão ameaçados, a educação brasileira vem sendo atacada por políticas de redução de recursos financeiros, corte de bolsas, não cumprimento do piso salarial em vários municípios brasileiros, além da redução de políticas de formação de formação de professores. Soma-se as salas de aulas de cheias, deixando os professores sobrecarregados, portanto, a educação está sendo destratada e sucateada no atual governo. 


\section{CONSIDERAÇÕES FINAIS}

A partir das reflexões ora apresentadas, podemos perceber a importância do PIBID no Colégio Estadual Adolfo Bezerra de Menezes, no município de Araguaína/TO, visto que o programa fornece elementos chaves no desenvolvimento e aplicação de novas metodologias, sempre de forma indissociável entre teoria e prática e acompanhamento e orientação dos professores da escola e da UFT.

Cabe salientar importância de trabalhar as oficinas de cartografia e jogo didático no colégio Adolfo, para compreensão dos alunos em relação a conceitos de território, paisagem, espaço e política, visto que a compreensão destes conceitos são fundamentais para o entendimento dos conteúdos de Geografia e da cartografia, possibilitando o exercício da cidadania de forma plena.

As contribuições do PIBID para a formação inicial de professores de Geografia foram demonstradas por meio de conhecimentos compartilhados e gerados, troca de saberes na prática docente e confecção de materiais didáticos, bem como fortalece a interação entre universidade e escola. Além de possibilitar a inserção de alunos no espaço escolar desde o início da graduação com reuniões e encontros frequentes.

Por meio do PIBID, os alunos se aproximam da escola, seu futuro local de trabalho, estabelecem calendários de atividades, articulando diversas instruções ao ensino/aprendizagem, além de relacionar a teria adquirida na universidade com a prática aplicada na escola, aspecto proporcionado pelo programa. Foi verificado, por meio do subprojeto de Geografia, que os alunos do PIBID/UFT cumpriram todas as suas atividades, metas e atividades propostas no planejamento do programa, adquirindo acúmulo e experiência nos processos educacionais.

Outro aspecto a ser destacado é o fator permanência, visto que com o PIBID os alunos se tornam mais motivados as atividades do curso, vivenciando a universidade como um todo e ainda contribuindo diretamente para uma formação crítica e reflexiva. Os alunos pibidianos geralmente desenvolvem seus trabalhos de conclusão de curso alguma temática do PIBID, contribuindo para a divulgação e sistematização do programa.

Portanto, o PIBID precisa ser fortalecido como política pública de fortalecimento de formação inicial de professores, com recursos financeiros garantidos, para que a sociedade se 
aproprie dos conhecimentos gerados tanto no âmbito das universidades, como escolas e que o programa possa servir de alicerce para a uma educação de qualidade.

Por fim, é importante destacar que os projetos PIBID estão sendo pressionados pelo corte de bolsas e alocação de recursos da educação para outras áreas. Não podemos retroceder e afirmamos que os investimentos na Educação Básica e no Ensino Superior devem ser públicos e primando pela qualidade, conforme previsto na Constituição Federal de 1988.

\section{REFERÊNCIAS}

ALMEIDA, Rosângela Doin de; ALMEIDA, Regina Araújo de. Fundamentos e perspectivas da cartografia escolar no Brasil. Revista Brasileira de Cartografia, Uberlândia/MG, v. 4, n. 63, p. 885-897, 2014.

BAGGIO, Lucilma Maria; CAMPOS, Ricardo Aparecido. Aproximando conceitos e práticas no Ensino de Geografia com o uso de recursos tecnológicos. Cadernos PDE, Jacarezinho/PR, v. 1, n. 1, p. 1-17, 2017.

BNNC. Base Nacional Comum Curricular. Ministério da Educação. Disponível em: http://basenacionalcomum.mec.gov.br/. Acesso em: set. 2019.

BRENDA, Thiara Vichiado. O uso de jogos no processo de ensino aprendizagem na Geografia escolar. 2013. 164 f. Tese (mestrado) - Universidade Estadual de Campinas, Instituto de Geociências, Campinas, SP, 2013.

BRASIL. Ministério da Educação. Secretaria de Educação Média e Tecnológica. Parâmetros curriculares nacionais para o Ensino Fundamental. Brasília: MEC/SEMTEC, 1997.

CALLAI, Helena Copetti. Aprendendo a ler o mundo: a geografia nos anos iniciais do ensino fundamental. Cad. Cedes, Campinas, v. 25, n. 66, p. 227-247, 2005.

CAPES. Coordenação de Aperfeiçoamento de Nível Superior. PIBID - Programa Institucional de Bolsa de Iniciação Científica. Disponível em: https://www.capes.gov.br/educacaobasica/capespibid/pibid. Acesso em: 21 set. 2019. 
CARVAlHO, Edilson Alves de; ARAÚJO, Paulo César de. História da Cartografia. Natal: EDUFRN, 2008.

FERRACINI, Rosemberg. Entrevista com a professora Dra. Sonia Castellar: da formação de professores ao livro didático. Revista Brasileira de Educação em Geografia, Campinas, v. 4, n. 8, p. 241-274, 2014.

FRANCISCHETT, Mafalda Nesi. A cartografia no ensino de geografia: a aprendizagem mediada. 2001. 219 f. Tese (doutorado) - Universidade Estadual de Campinas, Faculdade de Ciências e Tecnologia, Campinas/SP, 2001.

FREIRE, Paulo. Pedagogia da autonomia: saberes necessários à prática educativa. São Paulo: Paz e Terra, 2011.

FREITAS, Anniele Sarah Ferreira de. Formar professores-pesquisadores numa escola de bacharéis: a cultura do Pibid de Geografia da Unicamp. 2016. 164 f. Dissertação (mestrado) Universidade Estadual de Campinas, Instituto de Geociências, Campinas, SP, 2016.

GERHARDT, Tatiana Engel; SILVEIRA, Denise Tolfo. Métodos de pesquisa. Porto Alegre: Editora da UFRGS, 2009.

LISBOA, Severina. Sarah. A importância dos conceitos da geografia para a aprendizagem dos conteúdos geográficos escolares. Revista Ponto de Vista, v. 4, n. 1, Viçosa, p. 23-35, 2007.

MARCEDO, Luiz Paulo Leopoldo. Formação continuada de professores e novas tecnologias. Merceio: EDUFAL, 1999.

MOURA, Jeani Delgado Paschoal; ALVES, José. Pressupostos teórico metodológicos sobre o ensino de geografia: elementos para a prática educativa. Geografia, Londrina, v. 11, n. 2, p. 309-319, 2002.

NUNES, Cely do Socorro Costa. Os sentidos da formação continuada de professores: o mundo do trabalho e a formação de professores no Brasil. 2000. 155 f. Tese (doutorado) Universidade Estadual de Campinas, Faculdade de Educação, Campinas, SP, 2000. 
OLIVEIRA, Anízia Conceição Cabral de Assunção. Competências didático-pedagógicas para o ensino de geografia e os desafios à prática docente. In: VI Colóquio Internacional: Educação e Contemporaneidade. São Cristóvão/SE, 2012, p.1-13.

PIMENTA, Sônia de Almeida; CARVALHO, Ana Beatriz Gomes. Elementos da didática: os diferentes métodos de ensino. Campina Grande/PB: EDUEP, 2008.

SANTOS, Cátia dos; PEDROTTI, Alceu; MATOS, Alda Lisboa de; SANTANA, Ana Paula Silva de. A cartografia e o ensino de geografia. Revista Geográfica de América Central, Costa Rica, v. 2, n. 47, 2011.

SOUSA, José Gilberto; KATUTA, Ângela Massumi. A cartografia no movimento de renovação da geografia brasileira e a importância do uso de mapas. São Paulo: Editora Unesp, 2001.

WOITOWICZ, Eliete; SCHLOSSER, Marli Terezinha Szumilo. Atribuições do PIBID na formação inicial de professores de Geografia. Bol. geogr., Maringá, v. 36, n. 1, p. 30-47, 2018. 